\title{
O espaço dividido nas cidades do século XXI
}

\author{
Maria Angela Faggin Pereira Leite*
}

\section{Resumo}

Acompanhar o pensamento de Milton Santos sobre as relações entre a técnica e a sociedade e entre a técnica e o território nos permite identificar, em seus escritos, a cuidadosa construção de um argumento que privilegia a dialética e mergulha no entendimento do espaço para discutir suas categorias analíticas - a configuração territorial, a divisão territorial do trabalho, as formasconteúdo - e seus recortes espaciais - a paisagem e o lugar, entre eles. Desse conjunto evolutivo de estudos destacam-se duas formulações importantes no âmbito das pesquisas e intervenções da arquitetura e do urbanismo: a noção de território usado e a proposição dos dois circuitos da economia nas cidades dos países em desenvolvimento. Não se trata, naturalmente, de discutir ou de comparar conceitos correntes nos campos da geografia e da arquitetura e urbanismo, mas de entender a mudança de patamar que se opera a partir do momento em que as idéias de um pensador como Milton Santos tornam-se objeto de trabalho e de reflexão incorporando-se, e só então, a outras áreas de conhecimento.

Palavras-chave: Circuitos econômicos; Território usado; Arquitetura e urbanismo; Categorias analíticas do espaço; Recortes espaciais.

Faculdade de Arquitetura e Urbanismo da Universidade de São Paulo (mapleite@usp.br).

Geosul, Florianópolis, v. 26, n.51, p 75-88, jan./jun. 2011 
LEITE, Maria Angela F.P. O espaço dividido nas cidades do século XXI.

The divided space in the 21 st. century cties

\section{Abstract}

To follow Milton Santos's thinking process on the relations between the technique and the society and between the technique and the territory allows us to identify, in his writings, the careful construction of an argumentation that privileges the dialectic and immerses in the understanding of space, in order to discuss its analytical categories - the territorial configuration, the territorial division of work, the forms-content - and its spatial patterns - the landscape and the place, among them. Two important questions within the architecture and urbanism research and intervention scope stand out from this evolutionary body of studies: the idea of used [or wasted] territory and the proposition of two economic circuits in the cities of the developing countries. Naturally it is not the case of discussing or of comparing current concepts in the geography and the architecture and urbanism fields, but of understanding the change of scale as from the moment in which the ideas of a master as Milton Santos become subject of work and thinking and only then are incorporated in other areas of knowledge.

Key words: Economic circuits; Used [or wasted] territory; Architecture and urbanism; Analytical categories of space; Spatial patterns.

A importância dada por Milton Santos aos problemas que cercam a cultura, o papel do intelectual e seu compromisso social na atualidade esteve sempre estreitamente relacionada com sua busca pela interpretação dos processos técnicos, econômicos e políticos do mundo contemporâneo e da sociedade brasileira em particular. Sua proposta metodológica, que parte do conceito de espaço como "uma instância da sociedade, ao mesmo título que a instância econômica e a instância cultural-ideológica" (SANTOS, 1985, pág.1) privilegia a periodização como chave para essa 
LEITE, Maria Angela F.P. O espaço dividido nas cidades do século XXI.

interpretação, para entender as diferenças entre os lugares e o modo como eles respondem, em sua organização cotidiana, às crises resultantes da modernização.

Como assinalou, porém, ao final dos anos 1990, período e crise superpõem-se em um mesmo momento hoje, de tal maneira que, em lugar das crises de transição que costumeiramente antecedem e encerram os diferentes períodos históricos, a crise é, ela mesma, a forma do período atual. Esse debate não é novo e comparece na obra de inúmeros autores, mas vem, freqüentemente, marcado por discursos prospectivos e orientados pela ideologização tecnológica que obscurecem a apreensão concreta das relações sociais e das condições de domínio do capital na sociedade contemporânea.

Para Milton Santos "o mundo é um conjunto de possibilidades e não apenas um conjunto de realidades ... outros mundos poderiam ser criados a partir dos mesmos materiais e é possível vê-los se a gente se detém a pensar na maneira como o mundo está funcionando hoje, na maneira como os pobres se apropriam da tecnologia" (SANTOS, 1996). Transformar esse interesse pelo mundo em sua inteligibilidade constituiu o cerne de sua preocupação intelectual e é essa característica que torna sua obra universal. A busca de conceitos claros para conceber o conhecimento e assim conceber o mundo em que vivemos atravessou-a por quase seis décadas. Nela, a percepção e a inteligibilidade do mundo estão enraizadas na formação sócioespacial, categoria de análise que comanda a evolução de seus estudos sobre o território e sobre a história do território brasileiro.

No desenvolvimento de sua argumentação sobre as relações entre a técnica e a sociedade e entre a técnica e o território, lentamente podemos acompanhar em seus escritos a cuidadosa construção de um pensamento que privilegia a dialética e mergulha no entendimento do espaço para discutir suas categorias analíticas a configuração territorial, a divisão territorial do trabalho, as formas-conteúdo - e seus recortes espaciais - a paisagem e o lugar, entre eles. É assim que, buscando precisar o espaço, vão se 
LEITE, Maria Angela F.P. O espaço dividido nas cidades do século XXI. sucedendo as formulações de totalidade, aceleração contemporânea, período técnico-científico-informacional, mundo, tempo, eventos, fluxos e fixos, objetos e ações, para finalmente desembocar, em "A natureza do espaço", na razão e na emoção, desmontando o pressuposto de uma causalidade linear entre o desenvolvimento técnico e as mudanças sociais e espaciais do mundo de hoje.

E desse conjunto evolutivo de estudos eu destacaria duas formulações que me parecem importantes no âmbito das pesquisas e intervenções da arquitetura e do urbanismo: a noção de território usado e a proposição dos dois circuitos da economia nas cidades dos países em desenvolvimento. Não se trata, naturalmente, de discutir ou de comparar conceitos correntes nos campos da arquitetura e do urbanismo, mas de entender a mudança de patamar que se opera a partir do momento em que as idéias de um pensador como Milton Santos tornam-se objeto de trabalho e de reflexão incorporando-se, e só então, a outras áreas de conhecimento que não a Geografia.

\section{Urbanização e metropolização}

Para Milton Santos, as cidades e em particular as metrópoles, se tomadas como totalidade, funcionam como um sistema de estruturas, um sistema global constituído de subsistemas interdependentes e complementares. Essa totalidade se ajusta aos diferentes aspectos da modernização, através das interrelações dos subsistemas entre si e com o todo, criando um equilíbrio que mantém sua integridade.

Em todo o Terceiro Mundo, a partir do último quartel do século XX, o processo de urbanização veio acompanhado de um processo de metropolização, um salto quantitativo e qualitativo. Esse movimento é contemporâneo do processo de mundialização por que passa o planeta e envolve todos os aspectos da vida social. É resultado da modernização contemporânea, que a globalização tornou irrecusável, modernização que é, ao mesmo tempo, seletiva 
LEITE, Maria Angela F.P. O espaço dividido nas cidades do século XXI.

e não igualitária, pois privilegia uma parcela da população ao mesmo tempo em que promove o desenvolvimento simultâneo de novas classes médias e de uma multidão de gente pobre, isto é, aquela parcela muito maior da população para quem essa modernização é perversa.

Nas metrópoles do Terceiro Mundo esse processo faz cristalizar-se, em pontos determinados do território, uma nova lógica ao mesmo tempo econômica, política, social e geográfica, correspondente a esse momento histórico. É para esses pontos que confluem os resultados contraditórios de um processo de modernização que impõe formas de atraso surpreendentes, fazendo dessas cidades, simultaneamente, repositórios dos elementos da modernidade e de uma grande massa de deserdados, gerados, em boa parte, como função dessa mesma modernização que, assim, vê acentuado seu caráter perverso.

No processo de urbanização e de metropolização, ao mesmo tempo em que há uma modernização das atividades, há, também, uma expansão da pobreza e é a isso que Milton Santos chama de involução metropolitana já que, de um lado, existe crescimento, mas este é acompanhado pela baixa do rendimento médio e pela expansão do número de empregos mal remunerados com suas correspondentes e precárias condições de vida. Portanto, a modernização de atividades é simultânea à expansão de formas econômicas menos modernas que abrigam uma parcela da pobreza urbana, permitindo a existência de um setor econômico diferenciado do setor do grande capital.

A involução metropolitana e a segmentação da economia são, assim, fenômenos correlatos e podem ser verificados tanto através da variável produção como através das variáveis distribuição e consumo, determinadas pelos salários e pelo emprego e relacionadas com o nível de renda da população e sua localização geográfica. E nos países subdesenvolvidos essa modernização incompleta é, a cada momento histórico, o traço mais sensível das transformações do espaço. Seu efeito mais evidente é a desvalorização, senão mesmo a destruição localizada, 
LEITE, Maria Angela F.P. O espaço dividido nas cidades do século XXI.

mas não homogênea, de formas e habilidades do passado, efeito que se representa concretamente na paisagem de nossas cidades.

\section{Urbanização corporativa}

Outra característica dos países do Terceiro Mundo destacada por Milton Santos é o caráter corporativo de sua urbanização e de suas metrópoles. A participação na modernidade contemporânea exige dos países periféricos um esforço de equipamento mais extenso e intenso do que as modernizações precedentes. Esse esforço reclama uma enorme massa de recursos utilizados na construção das infra-estruturas econômicas, de tal maneira que o processo de incorporação do país à globalização dá-se em detrimento dos investimentos sociais exigidos por uma demografia e uma urbanização galopantes. Como somente poucas firmas podem realmente utilizar, em escala nacional, as infra-estruturas assim instaladas, a modernização conseqüente é seletiva, deixando de fora dos benefícios, mas não das cidades, uma parcela importante da atividade urbana e da população. Cidade abastada e cidade pobre formam, assim, uma só cidade.

Valeria a pena, aqui, relembrar um conceito, de modo geral familiar aos economistas e planejadores, que é a noção de economias e deseconomias urbanas. Diz-se que a cidade se torna deseconômica quando as condições de realização da chamada economia moderna já não são aí as melhores. Por isso faz-se um novo plano urbano ou atualiza-se o já existente, visando a criar novas economias urbanas, de modo a viabilizar, de novo, a produção. Na verdade, esse conceito é uma faca de dois gumes, pois a urbanização corporativa pode tornar o mesmo espaço construído uma deseconomia para as firmas muito grandes e, ao mesmo tempo, uma economia para as pequenas firmas. É por isso que os pobres e a economia pobre se instalam dentro das cidades e, muitas vezes, no seu centro, que abriga atividades consideradas menos nobres em áreas abandonadas pelas atividades mais poderosas. 
LEITE, Maria Angela F.P. O espaço dividido nas cidades do século XXI.

Por outro lado, em função dos objetivos em que se apóia e das relações que cria, a divisão internacional do trabalho promove, na atualidade, uma verdadeira mundialização dos lugares e essa mundialização permite a criação tanto de lugares especializados quanto de lugares complexos. Os lugares especializados para responder a uma demanda mundializada consagram-se a uma tipologia limitada de atividades exigentes de infra-estruturas precisas e também especializadas. Os lugares complexos são, habitualmente, as metrópoles e grandes cidades, onde o meio humano permite a floração de uma multiplicidade de atividades localmente complementares e, nos diversos subespaços metropolitanos, o meio técnico é adaptado e diferenciado para recebê-las.

Lugar composto e complexo, cada grande cidade inclui, pois, subespaços especializados, fundados na ciência e na técnica, concebidos para permitir, de um ponto de vista geoeconômico, a maior eficácia possível a um determinado tipo de função. Dispersão e concentração dão-se, assim, de modo dialético, isto é, de modo complementar contraditório e é desse modo que algumas cidades se impõem como metrópoles onipresentes, por isso mesmo e ao mesmo tempo, como metrópoles irrecusáveis para todo o território.

É, nesse sentido, nas palavras de Milton Santos, abusivo falar de cidades internacionais porque em todos os sistemas urbanos há componentes e aspectos internacionais que constituem um subsistema inseparável do resto. O mesmo pode ser dito dos organismos urbanos resultantes, pois estes associam, em uma única lógica, as lógicas individuais particulares dos subsistemas internacional, nacional e local, quando não regional e a própria paisagem urbana testemunha essa associação de influências.

\section{Território usado}

O conceito de território usado, criado por Milton Santos para pensar o real como objeto de pesquisa e de intervenção, envolve a 
LEITE, Maria Angela F.P. O espaço dividido nas cidades do século XXI.

consideração do acúmulo de tempos não em si mesmos, mas correlacionados à indissociabilidade entre forma e conteúdo, tanto resultado do processo histórico, quanto base material e social das novas ações humanas. "O território já usado pela sociedade ganha usos atuais que se superpõem e permitem ler as descontinuidades nas feições regionais. Certas regiões são, num dado momento, mais utilizadas e, em outro, o são menos. Por isso, cada região não acolhe igualmente as modernizações nem seus atores dinâmicos cristalizando usos antigos e aguardando novas racionalidades", afirma Milton Santos em "A natureza do espaço".

O território usado é o resultado da agregação sucessiva de sistemas técnicos aos lugares, é a materialidade desses lugares, mas também o registro dos eventos que os atingem e transformam, das ações que conferem significado ao processo dialético de sua existência. Sua conceituação envolve, além de considerações sobre o aparelhamento técnico-científico-informacional do território, o reconhecimento de sua capacidade de acolher a ação social solidária - o modelo cívico adotado pela sociedade. É importante lembrar que a sociedade exerce permanentemente um diálogo com o território e que esse diálogo inclui todas as coisas naturais e artificiais, a herança social e a sociedade em seu movimento atual, com todos os seus conflitos e valores. "O território só se torna utilizável para a análise social quando o consideramos com base em seu uso, quando o pensamos juntamente com os atores que dele se utilizam" (SANTOS, 2000, pág.22).

$\mathrm{O}$ recurso à idéia de território usado permite compreender que a renovação contínua da técnica - conjunto de instrumentos objetivos à disposição dos atores sociais - se impõe conflitos aos lugares, também os obriga à cooperação e à escolha de um presente possível.

E é por meio do lugar que Milton Santos pensa a vida humana em suas dimensões cognitiva e afetiva, como um comportamento que agrega valor à existência por meio da experiência. "O lugar é o cotidiano, mas é, ao mesmo tempo, os futuros nele contidos, inclusive os que lhe foram negados no 
LEITE, Maria Angela F.P. O espaço dividido nas cidades do século XXI.

passado. Assim o lugar é materialidade e sociabilidade mas, também, o conjunto dos eventos que o atingem e transformam" (RIBEIRO, 2004, pág. 45).

O conhecimento da cultura, da técnica e da política é a base para o entendimento do cotidiano e seus tempos, diferentes para as diferentes camadas sociais, mas unitários na conformação dos lugares. Os lugares - e as cidades são lugares - é que dão conta do mundo, porque existe neles "uma empiricização do mundo, uma empiricização de possibilidades latentes que é preciso conhecer para reformular o conhecimento" (SANTOS, 2000, pág. 52).

Os recursos da sociedade - naturais, territoriais, culturais, estéticos, materiais, políticos - estão sempre e permanentemente em disputa. Parece, assim, cada vez mais urgente referenciar as discussões da arquitetura não apenas na noção de território usado, que contempla de forma abrangente essa disputa, como também na formação sócio-espacial e suas relações horizontais e verticais, proposta fundante do pensamento de Milton Santos.

Em seu livro "Espaço e sociedade" (1979), ao propor a formação sócio-espacial como categoria de análise, Milton Santos apontou a existência, nas grandes cidades dos países em desenvolvimento, de dois subsistemas de fluxo econômico, complementares e interdependentes, cada um sendo um subsistema do sistema global que a cidade representa ${ }^{1}$.

A interrelação entre as estruturas horizontais, internas da sociedade - o circuito inferior da economia, a sociedade civil, as contigüidades espaciais, a comunicação - e as verticais, as relações inter-sociais - o circuito superior da economia, o mercado, as redes, a informação - resultam numa dialética local/extra-local que empresta aos lugares do território características únicas de organização. E, prossegue, assim como tem sido refutada a

Santos, 1979, pág. 36/54. Essa formulação inicial publicada pela primeira vez em Antipode, n ${ }^{\circ} 1$, vol.9, jan/fev 1977 foi, posteriormente, objeto de sucessivos aprofundamentos até resultar na obra "O espaço dividido", publicada no Brasil também em 1979. 
LEITE, Maria Angela F.P. O espaço dividido nas cidades do século XXI.

existência de um dualismo econômico e social nesses países, devese refutar o conceito de dualismo urbano - formal/informal ou legal/ilegal - na descrição, análise e interpretação da organização espacial de suas cidades.

Se a superação, ainda não da instabilidade em si, mas do impasse que leva à coexistência dos dois circuitos econômicos numa mesma sociedade exige a adoção de uma política de desenvolvimento que conduza a um crescente equilíbrio entre os padrões de consumo dessa sociedade, essa superação não prescinde, no campo do projeto ou da intervenção urbana, do reencontro ou da retomada de valores culturais permanentes, da garantia de espaço para a realização das potencialidades da cultura, tarefas que a arquitetura não pode mais desconsiderar. A combinação entre as noções de território usado e circuitos econômicos pode oferecer uma outra perspectiva a esse debate sobre a produção do urbano no Brasil, pois é nas cidades que se verifica uma oposição mais rápida e fácil à verticalidade - ao espaço produzido pelas escolhas que o circuito superior da economia faz de pontos do território necessários `a sua manutenção. E são também elas os domínios da horizontalidade do espaço banal, onde tudo está contemplado, onde se realiza a vida coletiva, onde estão presentes os que mandam e os que não mandam, os ricos e os pobres, os poderosos e os não poderosos. Nas cidades há surpresa e "a surpresa é a mãe da novidade; em uma situação aguda de crise ou de violência não é anormal que a sociedade urbana aponte para as desordens produzidas pela historia contemporânea e, ao mesmo tempo, para uma vontade de entendimento e superação" (SANTOS, 2000, pág. 61).

Parece, ainda, importante pensar o país a partir dessas noções porque é preciso explicitar as bases territoriais que preparam e recebem os diferentes tipos de produção, que não se processa igualmente em todos os lugares. 
LEITE, Maria Angela F.P. O espaço dividido nas cidades do século XXI.

\section{Presente e existente}

O caminho de entrada para essa discussão é a fluidez real, a livre circulação e utilização das estruturas e dos tempos do território por todos os seus atores. Importa indagar sobre as possibilidades de convivência - no sentido amplo - que se criam pela horizontalidade, pelas relações de contigüidade entre seus diversos lugares e pela solidariedade em contraposição à unificação determinada pela verticalidade, pelo uso homogêneo e pragmático do território para atender a determinações externas a ele. E importa, também, indagar sobre a ação do Estado, sobre seu interesse em intervir diferenciadamente sobre o território para assegurar, aos lugares que o integram, condições de permanência ou reconstituição das formas culturais de sua sociedade.

A paisagem, acumulação desigual de tempos, é tanto a expressão dos desejos coletivos na organização dos lugares de um território, quanto um registro de eventuais protestos contra as transformações nos objetos, nas ações, no modo de produção, impostas a esses lugares pela modernização - os futuros que lhes foram negados. E, para que seja assim entendida, a noção de território usado é essencial porque as formas da paisagem sínteses localizadas do sistema de objetos e o sistema de ações são qualificadas por uma sociedade que reage ao Estado e suas determinações com as armas de que dispõe, culturalmente introjetadas nas diversas classes sociais com base no modo como vivenciam esse território usado - o espaço de todos, todo o espaço - e seus lugares de vida.

A reflexão, a crítica e a conseqüente manifestação de anseios sobre a cidade não são consenso entre as diferentes classes sociais. São as necessidades não preenchidas em cada uma delas que alimentam os sonhos ou as utopias de participação social na produção de formas e objetos urbanos que propiciem o encontro, a comunicação, a discussão, a proposta e as ações para o preenchimento dessas necessidades. 
LEITE, Maria Angela F.P. O espaço dividido nas cidades do século XXI.

A insistência em fincar as estacas dessa discussão no existente, tomando-o como parâmetro das intervenções ou das propostas da arquitetura e do urbanismo não se justifica se procurarmos na proposição dos dois circuitos econômicos ou na definição de território usado os fundamentos para a compreensão da realidade. Sob a ótica dessas formulações teóricas, objetos e ações são interdependentes e, por isso, não têm existência autônoma, nem mesmo se o existente for entendido como campo de conhecimento do real ou, simplesmente, como estratégia de intervenção - o sistema de objetos sobre o qual incidem as intervenções projetuais materiais. "Categorias fundamentais como o homem, a natureza, as relações sociais, estarão sempre presentes como instrumentos de análise, embora a cada período histórico o seu conteúdo mude. É por isso que o passado não pode servir como mestre do presente e toda tarefa pioneira exige do seu autor um esforço enorme para perder a memória, porque o novo é o ainda não feito ou ainda não codificado. O novo é, de certa forma, o desconhecido e só pode ser conceitualizado com a imaginação e não com certezas" (SANTOS, 1980, pág. 8)

É o presente que nos interessa. O presente é conflitivo, é um terreno fértil para a imaginação, é uma escolha de futuros possíveis a se realizarem num determinado ponto de nossa trajetória. Quando, a exemplo do que ocorre nas cidades atuais, o número de possibilidades concretas é ampliado pela ampliação da diversidade social, cultural e econômica, os futuros possíveis tornam-se mais numerosos e mais próximos de nós e nossos projetos e utopias devem ser construídos com base nessas possibilidades, com base no que existe como germe e, por isso, se apresenta como algo factível. A intervenção deve ser, portanto, sobre o presente, que é muito diferente do existente porque o existente é uma materialidade possível do presente e está contido nele, assim como todos os conflitos que lhe são característicos e inerentes.

Ademais, no Brasil, o existente é altamente discriminatório e representativo da hegemonia social e financeira de algumas parcelas da sociedade e não serve de base para nenhum tipo de 
LEITE, Maria Angela F.P. O espaço dividido nas cidades do século XXI.

proposta que pretenda ser inovadora ou vanguardista sob o ponto de vista cultural ou, mesmo, que possa potencialmente contribuir para a reversão da miséria, da marginalidade, da injustiça e da segregação em que vivemos mergulhados.

Os conflitos entre os grupos sociais são desafios que, na atualidade, vão muito além daqueles determinados pelo sistema de produção e não encontram mais qualquer possibilidade de solução em planos e políticas que se apóiam em totalidades homogêneas. Numa estrutura social em que a velocidade e a informação comandam o comportamento individual e coletivo, a padronização do espaço de vida parece cada vez mais sem sentido. Certamente, as formas mais sutis e, por isso mesmo, mais profundas de relacionamento social - aquelas que atingem diretamente os planos ético e estético - são as que mais se ressentem do exílio da espontaneidade na organização dos lugares de vida da sociedade contemporânea.

Essa, entretanto, é uma discussão que apenas se inicia, demandando estudos aprofundados e discussões serenas que permitam operar uma urgente e já tardia mudança de patamar de entendimento da paisagem como categoria de análise ou como recorte espacial na discussão da segregação urbana neste início de século. E a maior homenagem que podemos prestar ao intelectual Milton Santos é apontar a influência que seu pensamento e suas propostas podem vir a ter sobre os rumos de outras áreas do conhecimento que, a exemplo da Geografia, também se ocupam do espaço.

\section{Referências bibliográficas}

BRANDÃO, Maria A. (org). Milton Santos e o Brasil. São Paulo, Fundação Perseu Abramo, 2004.

DIAS, Leila Christina, "Técnica, território e poder na obra de Milton Santos”. In Brandão, Maria A. (org). Milton Santos e o Brasil. São Paulo, Fundação Perseu Abramo, 2004. 
LEITE, Maria Angela F.P. O espaço dividido nas cidades do século XXI.

PEREIRA LEITE, Maria Angela Faggin (org). Milton Santos/Encontros. Rio de Janeiro, Azougue, 2007.

Ribeiro, Ana Clara Torres, "Lugares dos saberes: diálogos abertos”. In BRANDÃO, Maria A. (org). Milton Santos e o Brasil. São Paulo, Fundação Perseu Abramo, 2004.

SANTOS, Milton. Espaço e Sociedade. São Paulo, Vozes, 1979.

SANTOS, Milton. O Espaço Dividido. São Paulo, Francisco Alves, 1979.

SANTOS, Milton. Por uma Geografia Nova. São Paulo, Hucitec, 1980.

SANTOS, Milton. Espaço e Método. São Paulo, Nobel, 1985.

SANTOS, Milton. Por uma Economia Política da Cidade. São Paulo, Hucitec, 1994.

SANTOS, Milton. A Natureza do Espaço. São Paulo, Hucitec, 1996.

SANTOS, Milton. Território e Sociedade. São Paulo, Perseu Abramo, 2000.

SANTOS, Milton, "Um encontro: Milton e Gil". In PEREIRA LEITE, Maria Angela Faggin (org). Milton Santos/Encontros. Rio de Janeiro, Azougue, 2007. 